\title{
Comentario
}

\section{Para repensar el patrimonio diez años después}

$\mathrm{C}_{\text {país preparan diversas actividades para conmemorar dos }}^{\text {ste año numerosos investigadores e instituciones de todo el }}$ acontecimientos que marcaron profundamente la historia de México: la Independencia de 1810 y la Revolución de 1910. Por supuesto que en todo este afán conmemorativo serán protagonistas las fuentes históricas que se relacionan con tan cruciales eventos y que se custodian en la Biblioteca Nacional de México (BNM) y el Archivo General de la Nación (AGN).

Sin embargo, no parece éste un periodo evocador que propicie reflexiones más profundas sobre el estado actual y las problemáticas que presentan ambas instituciones nacionales, ni tampoco para preocuparnos por el valor que tiene nuestro legado bibliográfico y documental y, por tanto, de cómo se lo transmitimos a las nuevas generaciones. Ninguna de estas cuestiones es baladí, al contrario, de estos aspectos depende en gran medida que la BNM y el AGN obtengan el reconocimiento institucional que merecen, y que éste pueda plasmarse en los espacios jurídico, institucional y social. No olvidemos que ambas entidades son baluartes institucionales cuya función principal ha sido salvaguardar los testimonios históricos de gran importancia para la memoria colectiva de los mexicanos.

Una empresa de tal magnitud requiere instituciones con recursos suficientes que puedan garantizar la permanente tarea de identificación y registro de esos objetos, y que todo ello redunde en la salvaguarda de sus colecciones y favorezca la transmisión de éstas entre las generaciones. Sin conocer con precisión las características de los objetos conservados no es posible realizar procesos de valoración, y se imposibilita también la 
planificación de cualquier política cultural específica sobre los bienes patrimoniales. Por eso debemos reconocer que la principal problemática de estas instituciones la conforma el registro de los bienes custodiados; cuestión que puede resolverse si nos abocamos a garantizar que un registro (bibliográfico o documental) se corresponda de forma inequívoca con un objeto resguardado.

Pero esto significa que debemos comprender que todo registro no sólo debe incluir la caracterización de los bienes de acuerdo con su naturaleza, sino también el reconocimiento de sus valores culturales y su estado de conservación. Con esta información estaremos en posibilidad de iniciar programas de conservación, valoración y socialización más acordes con la realidad de las colecciones. Sólo que un esfuerzo de esta naturaleza que no tome en cuenta las posibilidades reales de las instituciones (materiales y financieras) para emprender semejante tarea y obtener resultados concretos programables y medibles, es una falacia absoluta.

Por eso es imprescindible reflexionar sobre el marco jurídico que debe amparar la función social que cumplen estas instituciones. Como es sabido, tanto para la BNM como para el AGN, ese marco no ha sido el más adecuado para garantizar el ejercicio de tal función. La legislación aquí implicada ha sido durante mucho tiempo un tema álgido, en especial por la dependencia institucional que actualmente tienen ambas instituciones. ${ }^{1}$

La dependencia institucional de la BNM siempre ha sido interpretada como un tipo de custodia, aunque no exista formalmente tal denominación en ningún texto normativo vigente, pero para algunos esta relación entre dos instituciones nacionales, la UNAM y la biblioteca, no es la más adecuada porque no permite la evolución del órgano bibliotecario de acuerdo con el tipo y naturaleza institucional que le corresponden, como se observa en otros países; para otros, en cambio, esa relación ha sido necesaria históricamente y ha garantizado la permanencia de la BNM.

Por lo que toca al AGN, en el 2006 se presentó una propuesta para crear una Ley Federal de Archivos que fue aprobada en la

1 Como se sabe el archivo depende desde 1917 de la Secretaría de Gobernación y la biblioteca está adscrita a la estructura de la Universidad Nacional Autónoma de México desde su fundación en 1910, condición que no ha cambiado con la obtención de la autonomía universitaria en 1929 y que se mantiene vigente desde 1945. 
Cámara de Diputados en marzo del presente año, y que pronto dictaminará el Senado de la República. Sin duda esta propuesta debe aplaudirse porque pone la atención en un asunto cultural de gran importancia pese a que los legisladores se hayan tardado tanto en considerarlo. Si bien éste no es el espacio correcto para analizarla, sí podemos anotar algunas cuestiones que nos parecen importantes.

Ciertamente la propuesta legal es acertada en la gran mayoría de sus planteamientos y se suma al esfuerzo realizado desde hace varios años por numerosos gobiernos de la Federación para regular sistemas estatales de archivos. Pero dicha norma podría haber incluido una mejor relación con el sector cultural y su propia normativa, y también sería bueno que reconociera que su idea de patrimonio documental está muy alejada de la postulada por la UNESCO, que rebasa el espacio de un archivo y de los objetos que ahí se contienen. Tal situación nos aleja de un trabajo colectivo que nos ha honrado con varias nominaciones "Memoria del Mundo", como otras dos que reconocen la riqueza documental del AGN.

Por otra parte esta propuesta debió respetar la autoridad que debe tener la BNM para valorar los libros como bienes patrimoniales, y por tanto reconocer a la biblioteca como institución nacional. En efecto, muchos de esos libros son insustituibles por su propia naturaleza, y la biblioteca conoce muy bien este tema porque custodia un gran conjunto del patrimonio libresco del país. Sin este reconocimiento se dificulta la transición de la biblioteca hacia un órgano normativo y rector de políticas que afectan y determinan esencialmente el futuro de ese patrimonio.

Todavía no podemos ni debemos celebrar eufóricamente la iniciativa legal, porque cualquier ciudadano sensato y responsable sabe que un dictamen negativo (entre muchos otros factores) puede entorpecer su aprobación definitiva y hacer que la propuesta se estanque en el tiempo y no consiga su publicación en el Diario Oficial de la Federación y con ello su plena vigencia. No está de más recordar que dicha publicación no es garantía absoluta para que la situación del archivo cambie en un país con tan escasa cultura jurídica. Esta condición no podrá cambiar mientras no exista un proyecto educativo nacional que contemple el cumplimiento de las leyes como un elemento sustancial de 
una democracia saludable, una que no puede sostenerse sin información clara y precisa, como la que corresponde al proyecto de una nueva sede para el AGN.

Todos aquellos que han entrado en contacto con la valiosa información custodiada en el AGN, han visto deteriorarse el espacio institucional tanto para vergüenza de nacionales como de extranjeros al compararlo con otras instituciones de similar realce. Un nuevo edificio es una buena noticia, pero este tipo de proyectos que no tenga un conocimiento más amplio y social, como los tiempos actuales lo demandan, puede resultar un fiasco como tantos otros que ha vivido la sociedad mexicana.

Todas estas iniciativas entre otras, deben conducirnos a reflexionar puntualmente si seguiremos orientándonos por ocurrencias culturales o bien por políticas culturales que fortalezcan un futuro viable que garantice la salvaguarda de nuestros objetos patrimoniales. Si optamos por el diseño de políticas culturales sensatas y responsables, entonces tendremos que pensar en un concierto de instituciones que cuente con la participación de la sociedad.

Son tiempos difíciles, es cierto. Pero las conmemoraciones nacionales deben tener un momento de cordura para que, como sociedad, demandemos una correcta atención a los asuntos de interés general como la justicia, la salud pública, la educación y, por supuesto, la cultura. Es momento de pensar si debemos seguir apostando por una vida política que ha mostrado su incapacidad para resolver los problemas sociales o es el momento de revertir el proceso para poner nuestras instituciones de cultura en el lugar que merecen, ya que no debemos olvidar que el AGN y la BNM resguardan las huellas del ideario de aquellos que soñaron con un país diferente.

\section{Idalia García}

